\title{
(Research Article) \\ Effects of Vertical Ground Motion on Flat Slab Structure
}

\author{
Jaydeep H. Chotaliya ${ }^{1 *}$, Dipak K. Jivani ${ }^{2}$. \\ ${ }^{I *}$ P.G.Student (Structural Engineering) Department of Civil Engineering, Darshan Institute of Engineering \& Technology Rajkot, Gujarat, INDIA \\ ${ }^{2}$ Head of Department of Civil Engineering, Darshan Institute of Engineering \& Technology Rajkot, Gujarat, INDIA
}

\begin{abstract}
This study presents the effects of vertical ground motion on flat slab structure. In current scenario, most of design codes including IS 1893-2016 suggest design for vertical acceleration component of earthquake as 2/3 of horizontal. During the recent earthquakes, the vertical component of ground motion found to be exceeding the horizontal component. It is therefore, necessary to study response of structure in this type of earthquake where peak ground acceleration (PGA) of vertical component may exceed 2/3 of the horizontal one. In this study time history analysis has been performed using 10 unscaled Near-source seismic records. For account of effect of vertical ground motions 5 different structural system has been considered including Drop, Shear wall and 3 flat plate with different thickness. Variations in different parameters like axial force in column, punching shear at slabcolumn joint, deflection of slab has been discussed. The results of the analyses shows that vertical ground motion can significantly affect flat slab system in terms of axial force fluctuations in column, punching shear and deflection in slab.
\end{abstract}

Keywords: vertical ground motion, vertical earthquake motion, vertical PGA, flat slab, flat plate, response of flat slab, time history analysis.

\section{Introduction}

A recent trend in building construction is to rest slabs directly on columns (with or without drop panels) without using any beams. This construction, commonly called flat slab. Flat slab is favored because of their aesthetic and economic advantages. Flat slab sway by large amount in seismic event due to its low lateral stiffness and punching shear failure is most serious failure in flat slab, if this happens surrounding connections must be able to carry redistributed forces otherwise it may lead to consecutive collapse of structure.

Vertical ground motion has been given little attention due to credence that vertical acceleration is usually lower than horizontal acceleration. During the recent earthquakes, the vertical component of the ground motion found to be exceeding the horizontal component.

Newmark and Hall (1982) recommend design vertical spectrum as $2 / 3$ of the design horizontal spectrum and it is adopted by most of the design codes including IS-1893 2016.

However, research of Papazoglou and Elnashai, (1996) noted that $\mathrm{V} / \mathrm{H}$ ratio is critical within $30 \mathrm{~km}$ from source and

${ }^{*}$ Corresponding Author: e-mail: jaydeepchtl@gmail.com,

Tel-+91-8780842327

ISSN 2320-7590

(C) 2021 Darshan Institute of Engg. \& Tech., All rights reserved
$2 / 3$ rule is found to be on conservative side for near source events.

L. Di Sarno, A.S. Elnashai and G. Manfredi studied seismic response of RC members subjected to horizontal and vertical ground motions recorded during the 2009 L'Aquila (Italy) earthquake. Nonlinear dynamic analysis were performed with 4 recorded ground accelerations. Results of the inelastic dynamic analyses show Average increase in the Compression load of column ranges between $175 \%$.

Hongliu Xia \& Jixin Lin considered 7 story plane frame structure to analyze the effect of vertical earthquake motions by time history analysis. It is noted When the ratio of $\mathrm{V} / \mathrm{H}$ is 1.31, the axial force of the interior columns even decreased 1.3 times of the axial force under gravitational load; it indicated that tension force occurred. Further when inputting horizontal ground motion only, the plastic hinges mainly occurred at the beam-ends of the frame. But under combined horizontal and vertical ground motion, the column hinges notably increased, especially increase of plastic hinges at middle floor columns.

Hossein Abdollahiparsa, Peyman Homami, and Faramarz Khoshnoudian investigated the effects of vertical components of earthquakes on the responses of 5, 15, and 25 story steel frames by taking into account Soil-Structure Interaction. Nonlinear time history analyses was carried out, 4 earthquake time histories were used for analysis. The results showed that the vertical component and SSI can increase the 

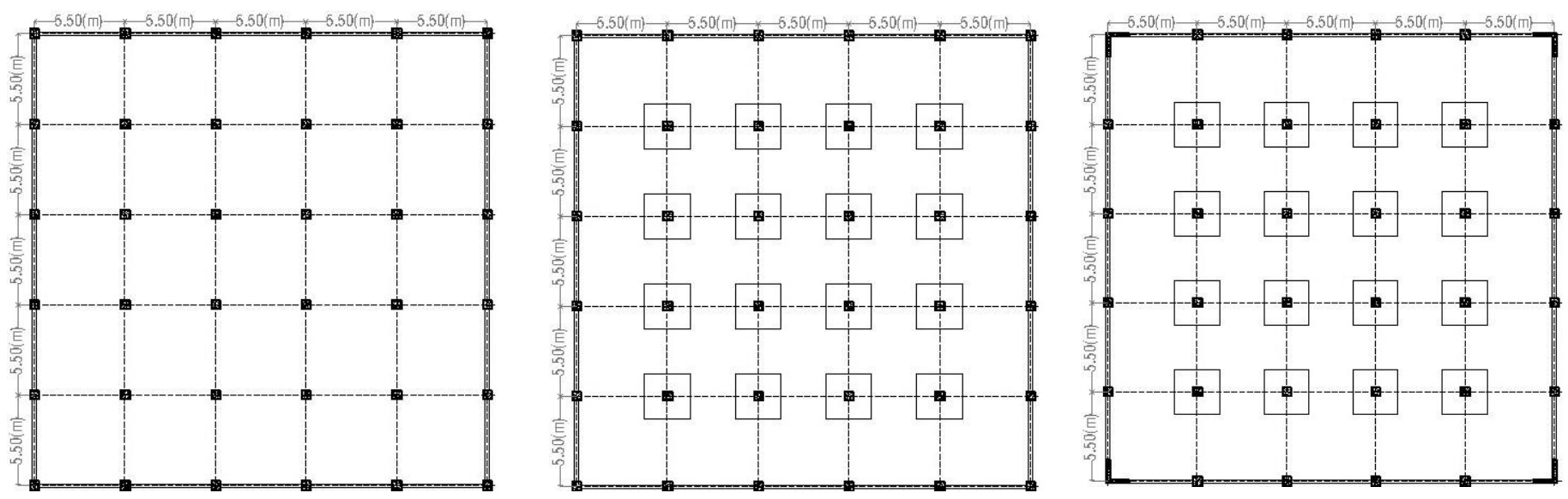

Figure 1: Layouts of Flat plate, Flat slab with Drop and Flat slab with shear wall building

axial force on columns by nearly $20 \%$ to $80 \%$. It was noted that when structure is rested on fixed based, changes in drift is negligible.

Siyun Kim, Sung Jig Kim, and Chunho Chang studied 13 $\mathrm{RC}$ frames with varying geometric arrangements including the differences in span length, span ratio and story height. Variation of column axial load at the ground story on account of vertical ground motion was reported to be as high as $240 \%$ when compared with the dead load. It is noted that the axial force variation due to vertical acceleration is increased as span length increase. It is observed that lateral displacement is mainly affected by horizontal ground motion rather than vertical ground motion.

P. C. Shaha, K. Palaniyandi and C.B. Nayak carried out study of effect of vertical ground motion on long span roof truss. The Time History Analyses are carried out for two cases: one with only horizontal ground acceleration and rest with horizontal plus vertical ground accelerations. Eight unscaled near-fault earthquake ground motion records involving of four with pulse and four without pulse were selected. From these analysis it is noted that there is a maximum of $53 \%$ increase in axial force of column, $78 \%$ Increase in vertical displacement of the truss at ridge level. In general design of roof truss is governed by wind load combination in but, in this study vertical ground motion component is governing the design for long span roof truss. These all studies concluded that axial force in column can be amplified by vertical seismic ground motion so in that case behavior of slab column connections need to be studied.

\section{Structural model and ground motion selection}

In this study we have considered 3 buildings $\mathrm{G}+7, \mathrm{G}+10$ and $\mathrm{G}+15$ with three different structural configurations flat plate, Flat slab with drop and flat slab with shear for each building wall as shown in fig. 1. For the flat plate structural system three different $\mathrm{L} / \mathrm{D}$ ratio $15,20,25$ is considered for slab to check the effect of slab thickness on punching shear and vertical acceleration. In all the models periphery beam is provided to avoid excessive value of punching shear stress at slab column junctions. 3 meter of story height is kept for all buildings.

For selection of ground motion records these criteria was considered: (1) Magnitude of earthquake $>6$ to avoid low intensity earthquakes (2) Epicenter distance $<30 \mathrm{kM}$ as this range is found to be critical in past study by Papazoglou and Elnashai and near source region is significantly affected by vertical acceleration during the 1994 Northridge and 2011 Christchurch earthquakes (3) V/H ratio > 2/3 $\quad$ (4) Non-pulse ground motion records only.

After screening out of earthquake records by these criteria from NGA-West2 database we have considered 10 unscaled seismic ground motions as shown in Table 2. So in this way we have analyzed around 150 models for different vertical ground motions.

Table 1: Details of flat slab models

\begin{tabular}{|l|l|}
\hline Plan area & $27.5 \mathrm{~m} \mathrm{X} \mathrm{27.5m}$ \\
\hline Story height & $3 \mathrm{~m}$ \\
\hline Spacing of Bays & $5.5 \mathrm{~m}$ in both direction. \\
\hline Column & $530 \mathrm{~mm} \mathrm{X} \mathrm{530mm}$ \\
\hline Periphery Beam & $230 \mathrm{~mm} \mathrm{X} \mathrm{450mm}$ \\
\hline Shear Wall & $2750 \mathrm{~mm} \mathrm{X} \mathrm{230mm}$ \\
\hline Drop & $2750 \mathrm{~mm} \mathrm{X} \mathrm{2750mm} \mathrm{X} \mathrm{100mm}$ \\
\hline $\begin{array}{l}\text { Slab thickness } \\
\text { (L/D ratio 15,20,25) }\end{array}$ & $360 \mathrm{~mm}, 275 \mathrm{~mm}, 220 \mathrm{~mm}$ \\
\hline Respectively \\
\hline Live load on floors & $3 \mathrm{kN} / \mathrm{m}^{2}$ \\
\hline Live load on roof & $1.5 \mathrm{kN} / \mathrm{m}^{2}$ \\
\hline Floor finish & $1.5 \mathrm{kN} / \mathrm{m}^{2}$ \\
\hline Grade of concrete & $\mathrm{M} 30$ \\
\hline Grade of reinforcement & $\mathrm{Fe}-415$ \\
\hline
\end{tabular}

To analyze all buildings under horizontal and vertical seismic acceleration linear time history method is adopted and ETABS v17 has been used. 
Table 2: Selected ground motion records

\begin{tabular}{|c|c|c|c|c|c|c|c|c|c|}
\hline EVENT & RSN & STATION & Mw & $\begin{array}{c}\text { ED } \\
(\mathrm{Km})\end{array}$ & H1 $(\mathrm{g})$ & H2 $(\mathrm{g})$ & $\mathrm{V}(\mathrm{g})$ & $\begin{array}{c}\text { V/H } \\
\text { RATIO }\end{array}$ & $\begin{array}{c}\text { REF. } \\
\text { NO. }\end{array}$ \\
\hline Gazli, USSR & 126 & Karakyr & 6.83 & 3.92 & 0.7 & 0.87 & 1.7 & 1.95 & GM1 \\
\hline Imperial valley USA & 183 & EL Centro array 8 & 6.5 & 3.86 & 0.6 & 0.46 & 0.47 & 0.79 & GM2 \\
\hline Morgan hill USA & 456 & Gilroy array 2 & 6.19 & 13.68 & 0.16 & 0.21 & 0.57 & 2.71 & GM3 \\
\hline Nahanni, Canada & 495 & Site 01 & 6.76 & 2.48 & 1.1 & 1.2 & 2.3 & 1.91 & GM4 \\
\hline Loma prieta USA & 752 & Capitola & 6.93 & 8.65 & 0.51 & 0.42 & 0.55 & 1.07 & GM5 \\
\hline Northridge USA & 949 & Arleta fire station & 6.69 & 3.3 & 0.35 & 0.3 & 0.55 & 1.61 & GM6 \\
\hline Kobe Japan & 1108 & Kobe University & 6.9 & 0.9 & 0.27 & 0.31 & 0.45 & 1.45 & GM7 \\
\hline Northwest china & 1752 & Jiashi & 6.1 & 10 & 0.3 & 0.25 & 0.38 & 1.26 & GM8 \\
\hline Chi-Chi, Taiwan & 3472 & TCU076 & 6.3 & 23.84 & 0.12 & 0.12 & 0.26 & 2.16 & GM9 \\
\hline Christchurch, New Zealand & 8090 & Hulverstone station & 6.2 & 17.86 & 0.19 & 0.27 & 1.1 & 4.07 & GM10 \\
\hline
\end{tabular}

*ED= epicenter distance, $\mathrm{Mw}=$ Magnitude of earthquake, $\mathrm{H} 1=$ Long. PGA, H2= Trans. PGA, V= Vertical PGA All earthquake ground motions are selected from PEER NGA WEST2 DATABASE.

\section{Analysis result \& discussion}

A linear time history analysis is performed for 10 selected ground motion records which is applied on 15 different structures. To compare the results of the analysis we will use notation of G7, G10 \& G15 to indicate building height and D, S, P15, P20, P25 to indicate structural system drop, shear wall flat plate with $\mathrm{L} / \mathrm{D}$ ratio $15,20, \& 25$ respectively.

\section{G15_D}

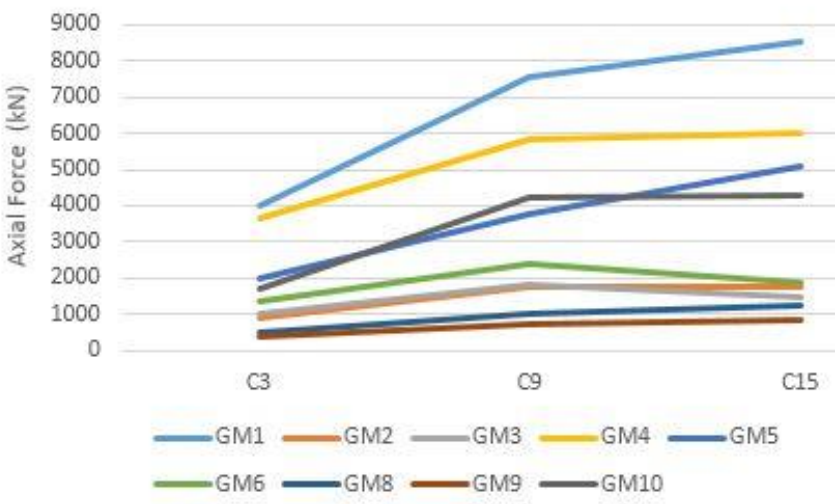

Figure 2: Axial force in G15_D columns.

\section{G15_S}

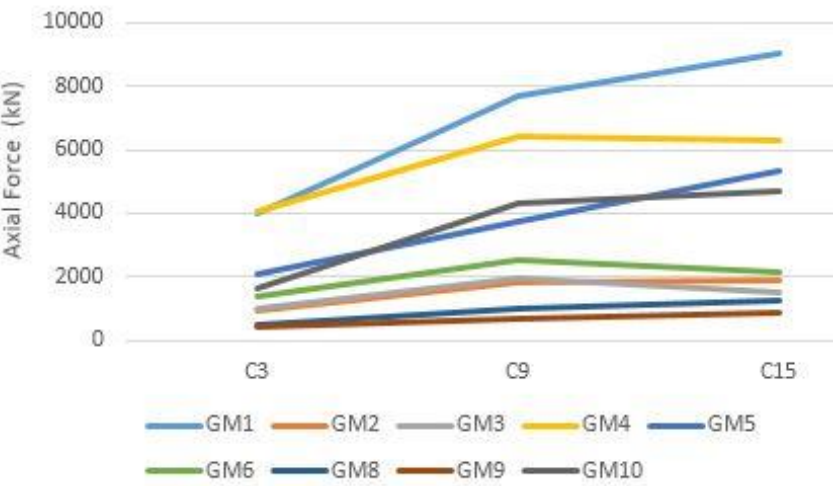

Figure 3: Axial force in G15_S columns.
To represent the result of axial force in column due to vertical acceleration we have selected 3 columns. Middle column in outer periphery that is $\mathrm{C} 3$, middle column in internal grid that is $\mathrm{C} 9$ and central column that is $\mathrm{C} 15$. Maximum axial force is found in ground story in all of the models, additionally some of column experienced axial tension load higher than axial compression. To represent the result as simple as possible we will not consider negative sign in this presentation.

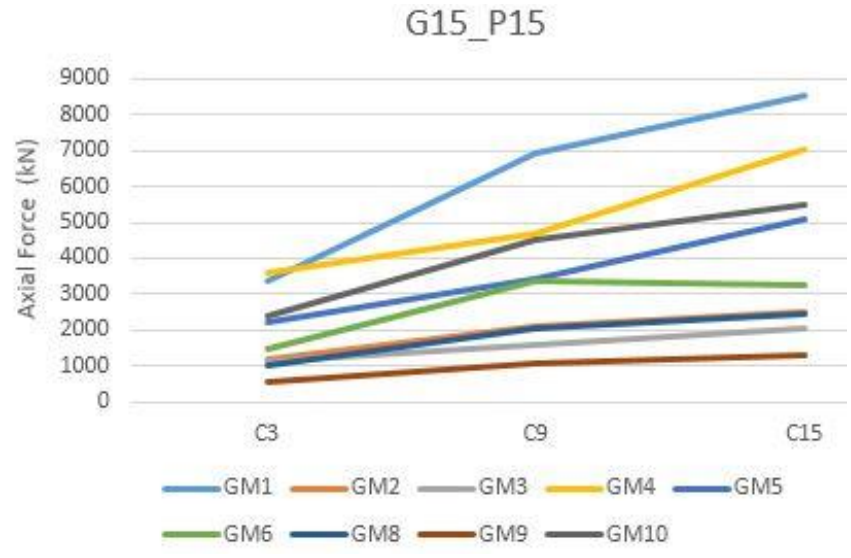

Figure 4: Axial force in G15_P15 columns.

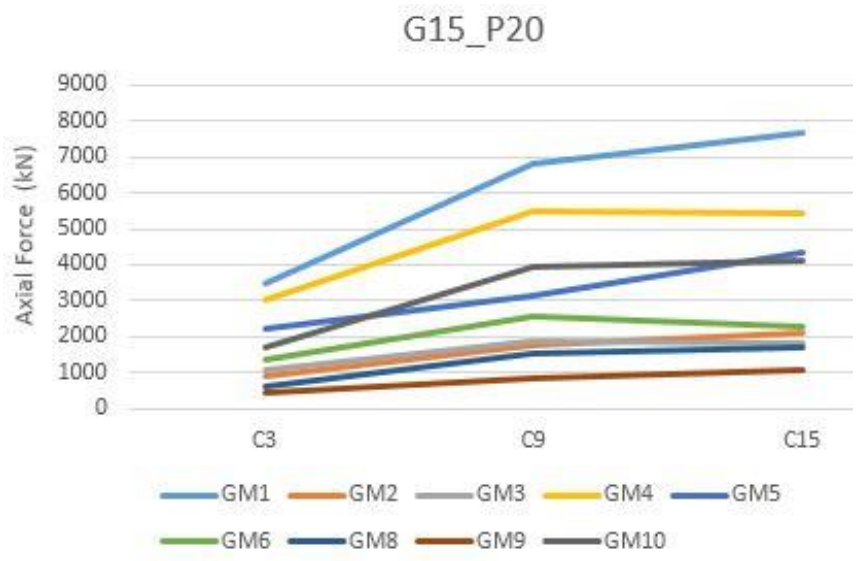

Figure 5: Axial force in G15_P20 columns. 


\section{G15_P25}

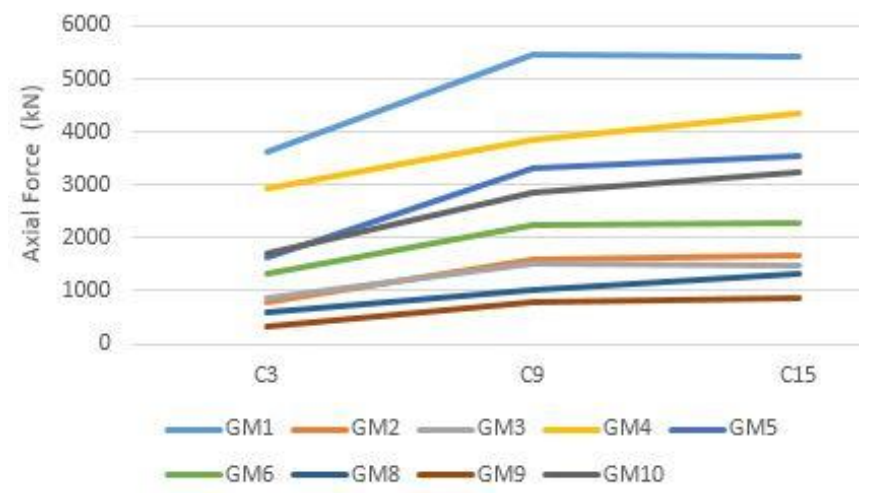

Figure 6: Axial force in G15_P25 columns.

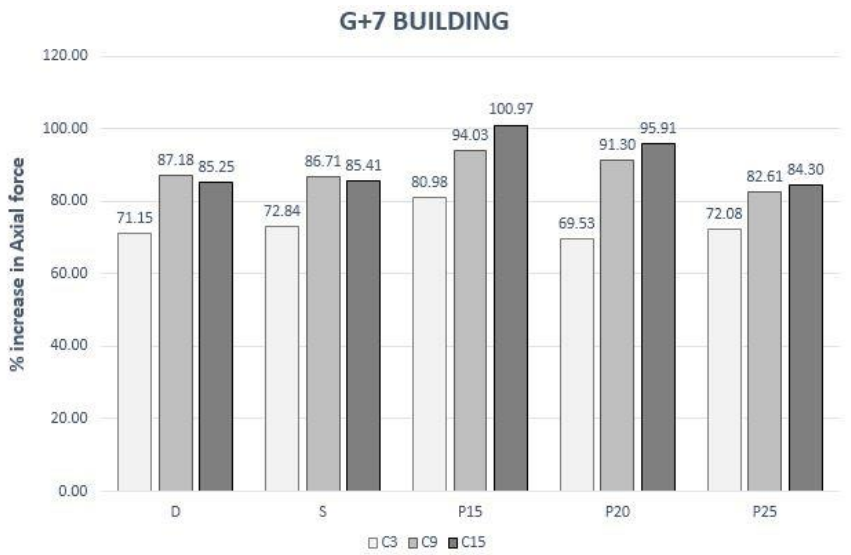

Figure 7: Average increase of axial force $\%$ in G+7

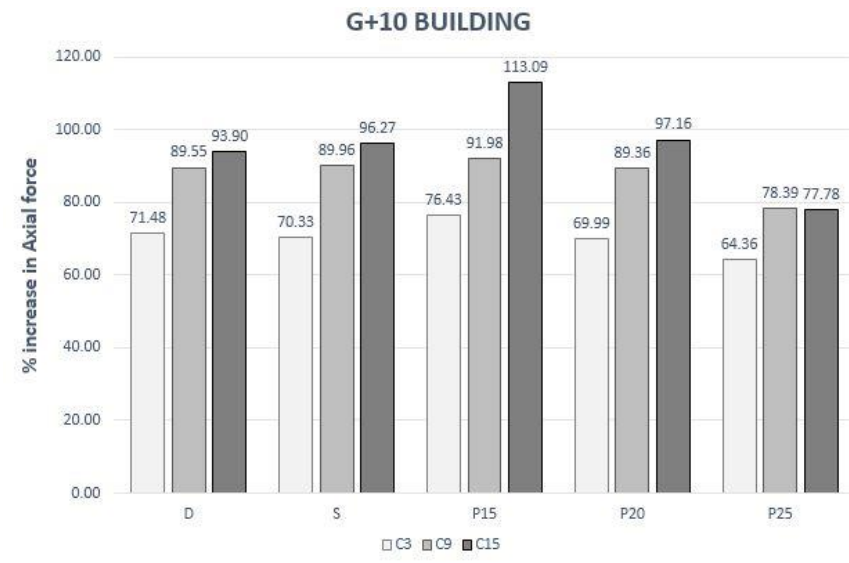

Figure 8: Average increase of axial force $\%$ in $\mathrm{G}+10$

Maximum axial compression due to gravity force and vertical acceleration is $6932 \mathrm{kN}$ and $8518 \mathrm{kN}$ respectively in $\mathrm{C} 15$ in G15_P15_GM1 while maximum axial tension due to vertical acceleration is $9032 \mathrm{kN}$ and gravity force is $5475 \mathrm{kN}$ in $\mathrm{C} 15$ in G15_S_GM1. So net tension will be $3557 \mathrm{kN}$ and maximum axial force due to vertical acceleration was $165 \%$ with compare to gravity force.
All the results of axial force in column for $\mathrm{G}+15$ model is presented in Fig. 2 to 6 however we will not go in results of columns of G+10 \& G+7 for each ground motions, instead of this we will see average values of percentage of axial force with compare to gravity force for given columns and structural system. This is presented in Fig. 7 to 10. From this results we found that axial force is increase in central columns and it will be minimum in outer periphery.

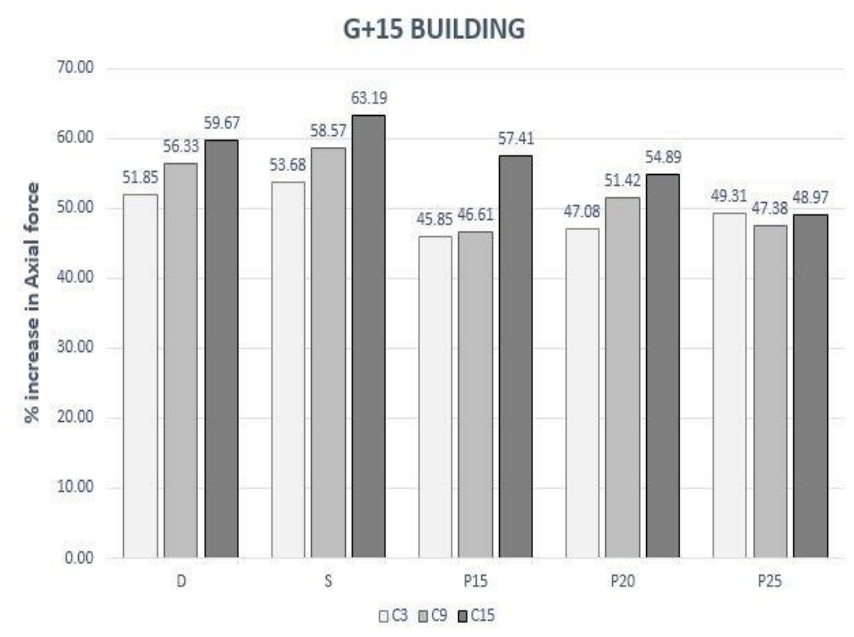

Figure 9: Average increase of axial force $\%$ in $\mathrm{G}+15$

Slab deflection is indicator of seismic response of flat slab structure. For each of the seismic ground motion and each model the deflection of slab is found to be maximum at center of the slab. Further global deflection of slab is higher on top floor and continuously decreasing in lower story due to axial shortening effect of the structure. Therefore, result of top slab is presented here in fig. 10 to 14 for different structural system of $\mathrm{G}+15$ building. Red line shown in these figure is indicating slab deflection due to gravity loads.
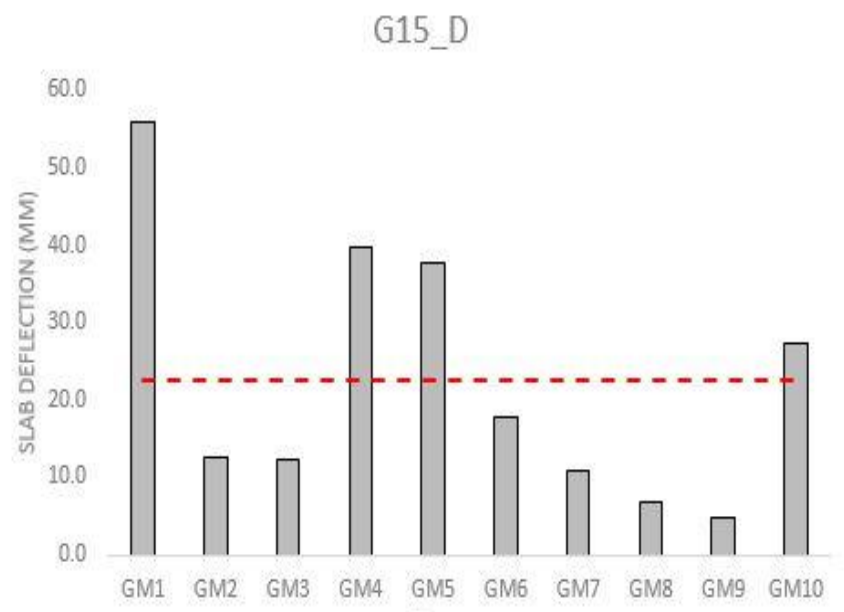

Figure 10: Deflection of slab in G15_D 
G15_S

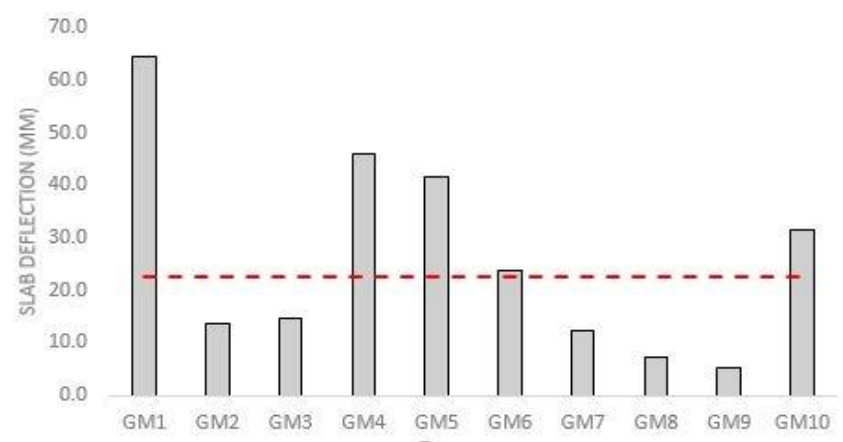

Figure 11: Deflection of slab in G15_S

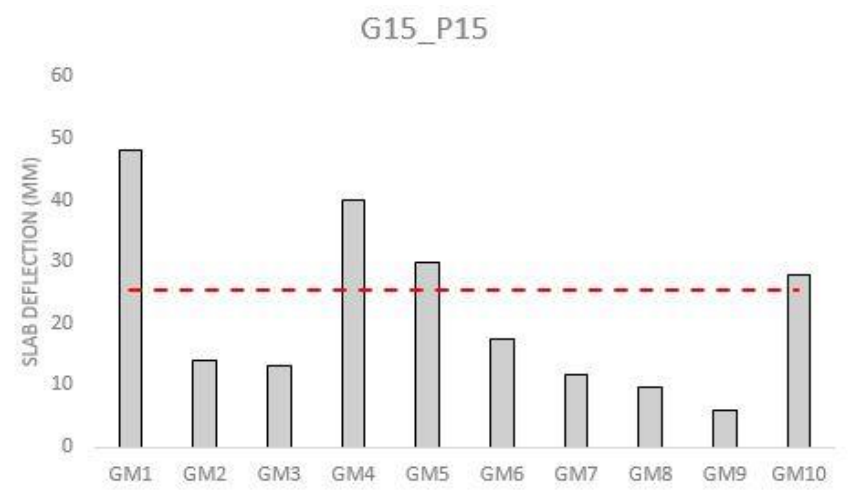

Figure 12: Deflection of slab in G15_P15

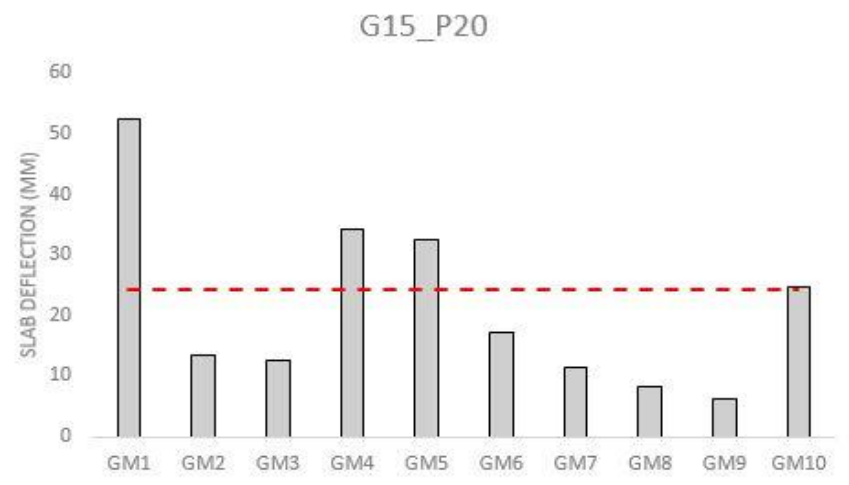

Figure 13: Deflection of slab in G15_P20

As we can see in these figures in more than $50 \%$ of the records deflection of slab due to vertical ground motion only is higher than deflection due to gravity forces. Maximum $64.7 \mathrm{~mm}$ slab deflection is produced due to vertical ground motion in G15_S while deflection due to gravity load for the same is $22.6 \mathrm{~mm}$. So total deflection will be $87.3 \mathrm{~mm}$ which is much higher than allowed in IS 456 for serviceable limit. This deflection may lead to damage non-structural elements and stiffness degradation of slabs.

Comparing drops without shear wall and drop with shear wall, it can be seen that deflection is increased in shear wall structure that indicating shear wall will not be able to control vertical deflection as it can decrease lateral deflection and

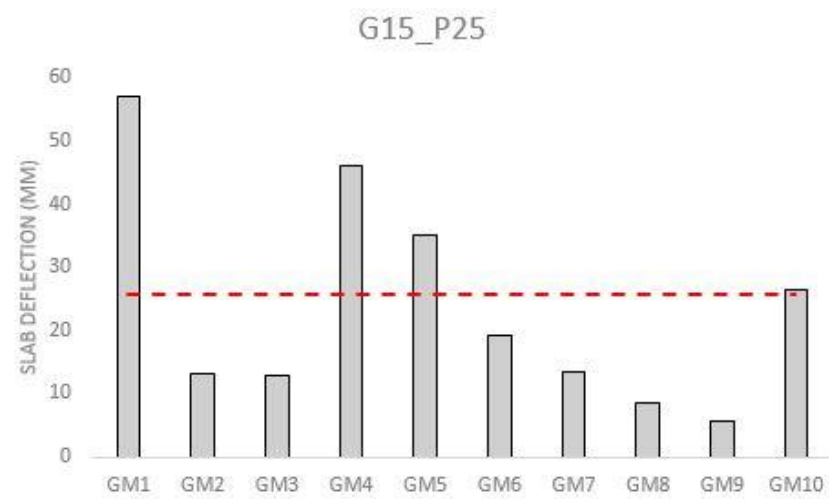

Figure 14: Deflection of slab in G15_25

drift of structure. Comparing to slab thickness, maximum deflection of P15, P20 \& P25 is $48.1 \mathrm{~mm}, 52.7 \mathrm{~mm} \& 57 \mathrm{~mm}$ while applying GM1 indicating deflection due to vertical seismic force will also be increase as thickness of slab decrease. Results for $\mathrm{G}+10$ and $\mathrm{G}+7$ are similar to this. We will not go further in this, instead we will see average deflection for all applied ground motions. Here deflection due to gravity load and vertical acceleration is indicated as $\mathrm{Uz}$ and Uzv respectively.

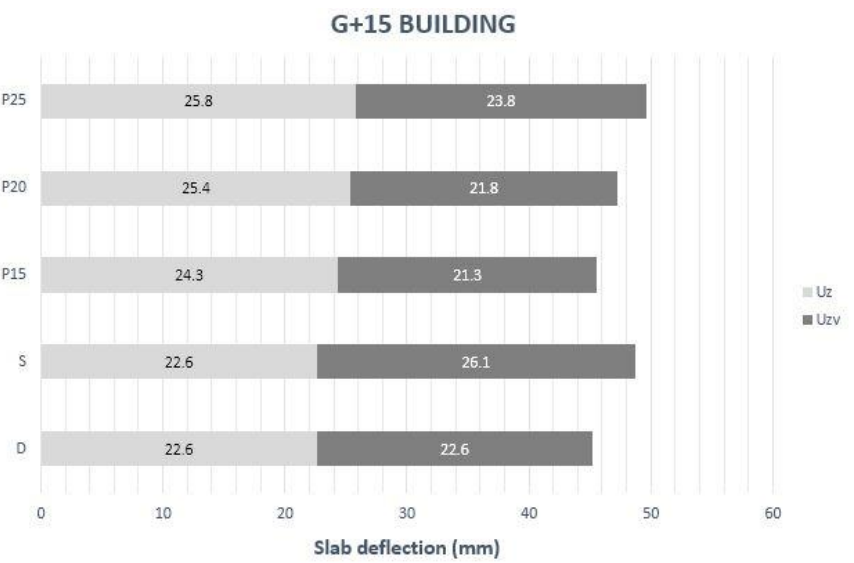

Figure 15: Average deflection of slab in G+15 Building.

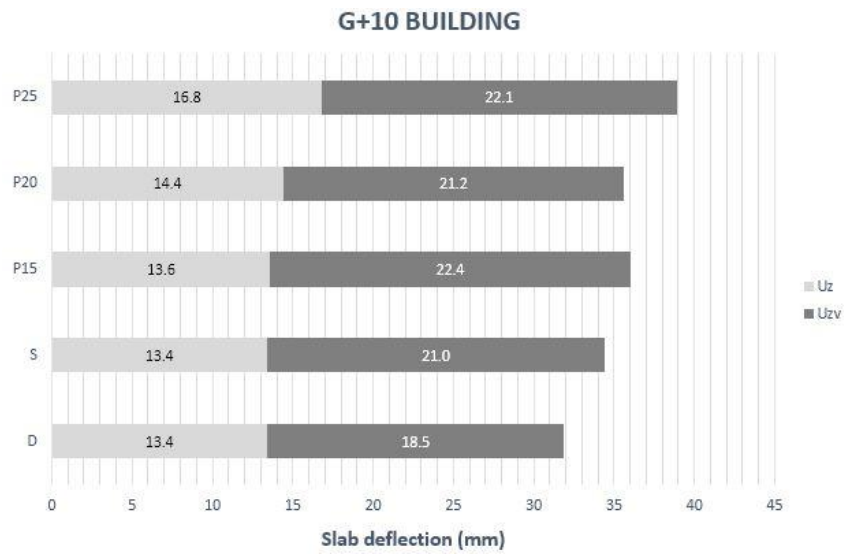

Figure 16: Average deflection of slab in G+10 Building 


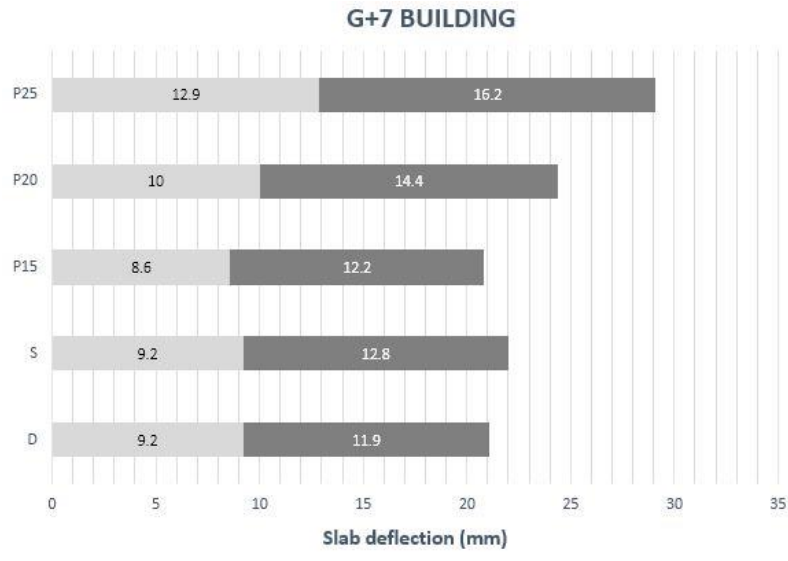

Figure 17: Average deflection of slab in G+7 Building

Punching shear failure is the most serious type of failure in flat slabs, this type of failure is dangerous because no visible signs are shown prior to failure. Vertical seismic acceleration can significantly increase both the vertical shear carried by a slab-column connection and slab local relative rotation. As we have seen that maximum effect of vertical acceleration is found in central column, results of punching shear is also found to be maximum at the slab column junction of $\mathrm{C} 15$ column. Red line in Fig. 18 to 22 is indicating punching shear stress due to gravity loads.

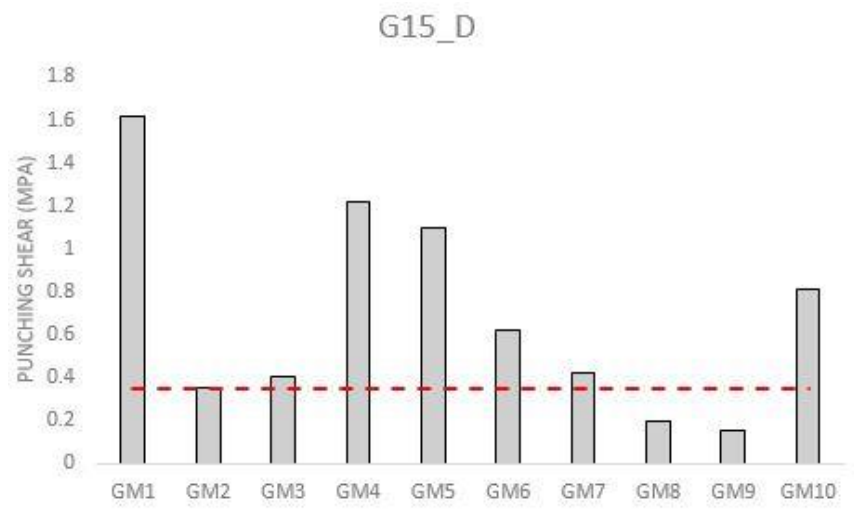

Figure 18: Punching shear stress in G15_D

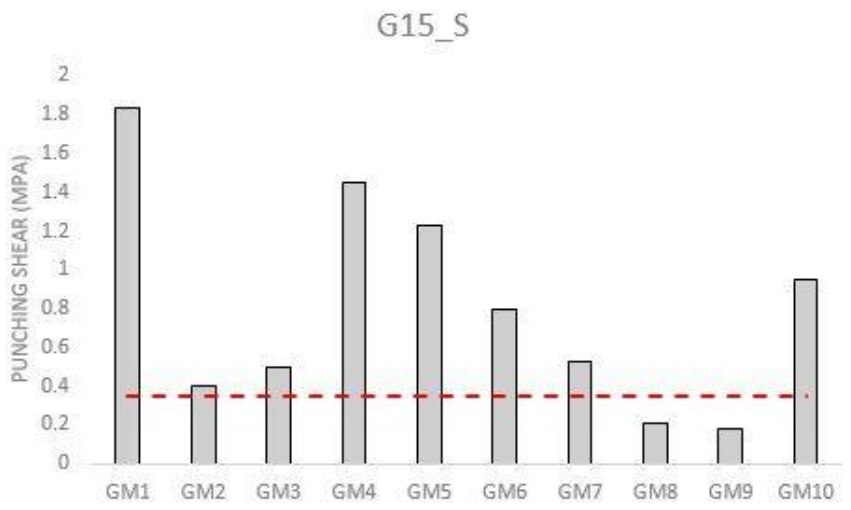

Figure 19: Punching shear stress in G15_S
G15 P15

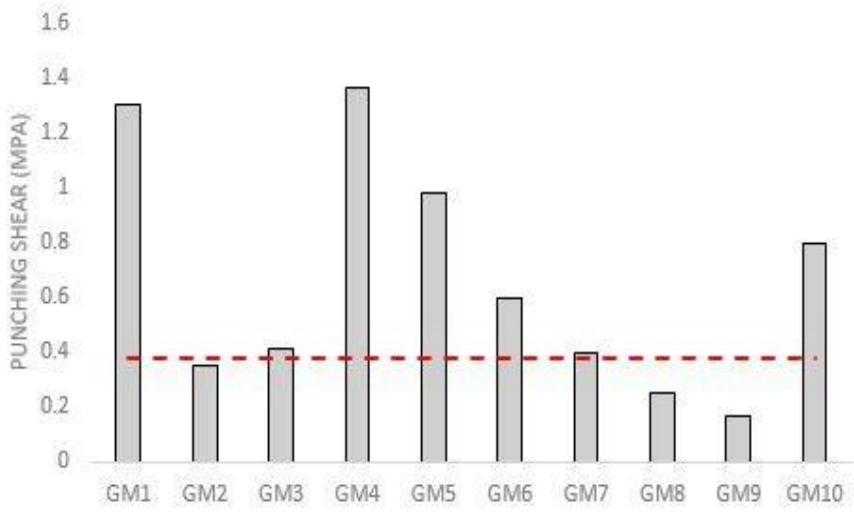

Figure 20: Punching shear stress in G15_P15

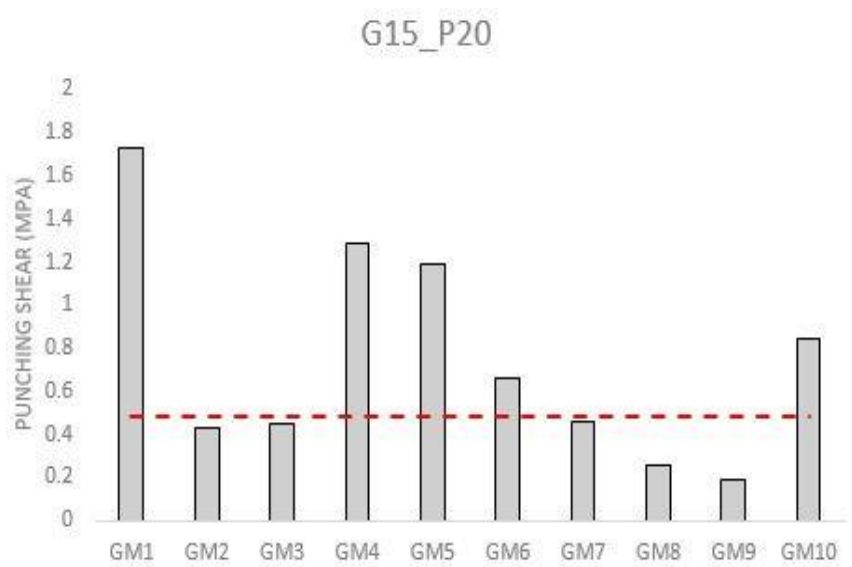

Figure 21: Punching shear stress in G15_P20

Results of punching shear failure are similar to the slab deflections. Maximum shear stress due to vertical seismic force is found $2.2 \mathrm{~N} / \mathrm{mm}^{2}$ in P25 building as it has minimum slab thickness.

\section{G15_P25}

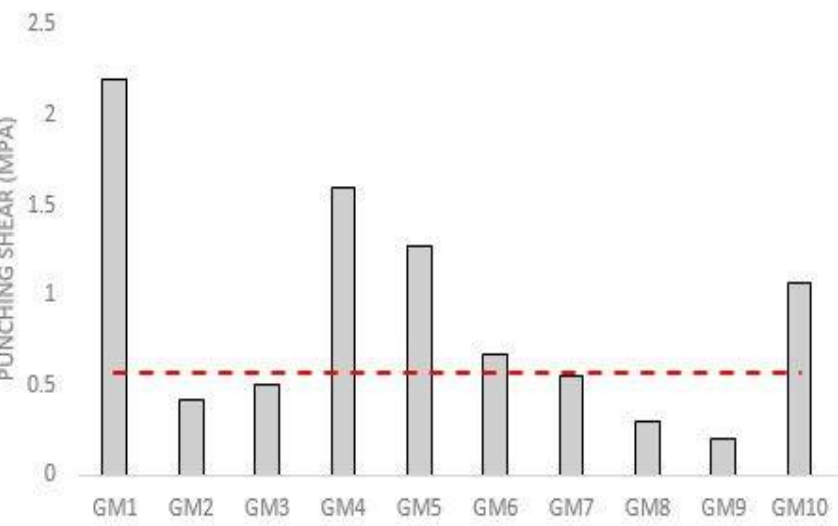

Figure 22: Punching shear stress in G15_P25 


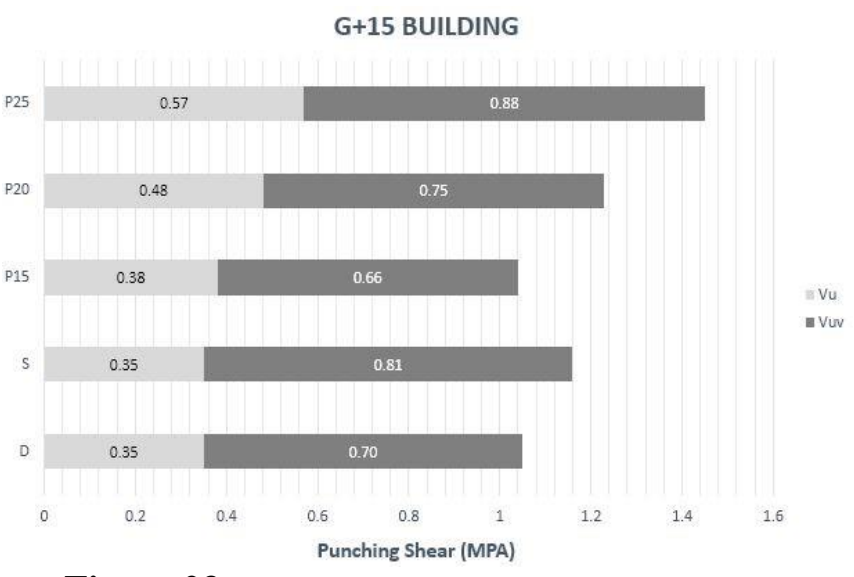

Figure 23: Average punching shear stress in $\mathrm{G}+15$

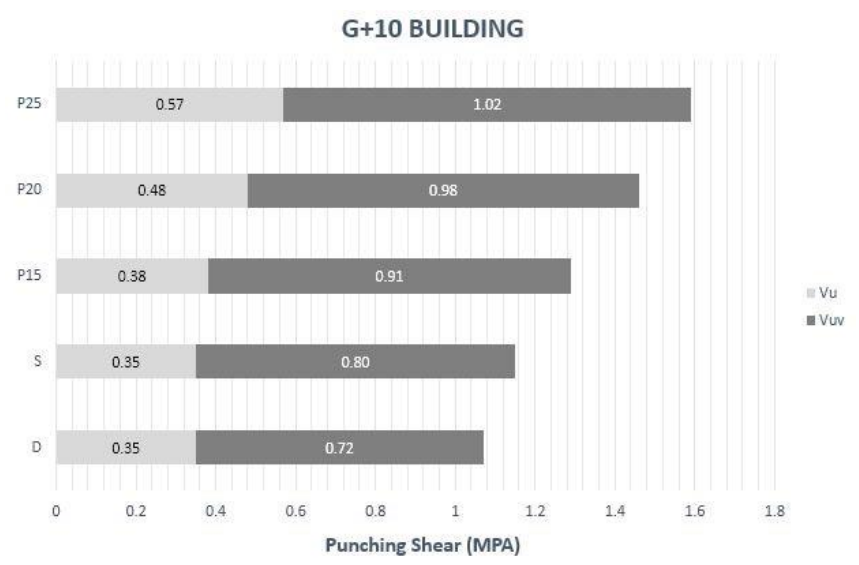

Figure 24: Average punching shear stress in G+10

Comparing to drop without shear wall and drop with shear wall, punching stress is increased in shear wall structural system. While in flat plate system punching stresses due to gravity force and vertical seismic force increase with decrease in thickness of slab. Maximum increase in punching stresses due to vertical forces with compare to gravity forces is $525.7 \%$ in G15_S under GM1. Average punching shear stress for $\mathrm{G}+7, \mathrm{G}+10$ \& $\mathrm{G}+15$ is shown in Fig. 23 to 25 , here $V_{\mathrm{u}}$ and $\mathrm{V}_{\mathrm{uv}}$ represents stresses due to gravity forces and vertical seismic forces respectively.

\section{G+7 BUILDING}

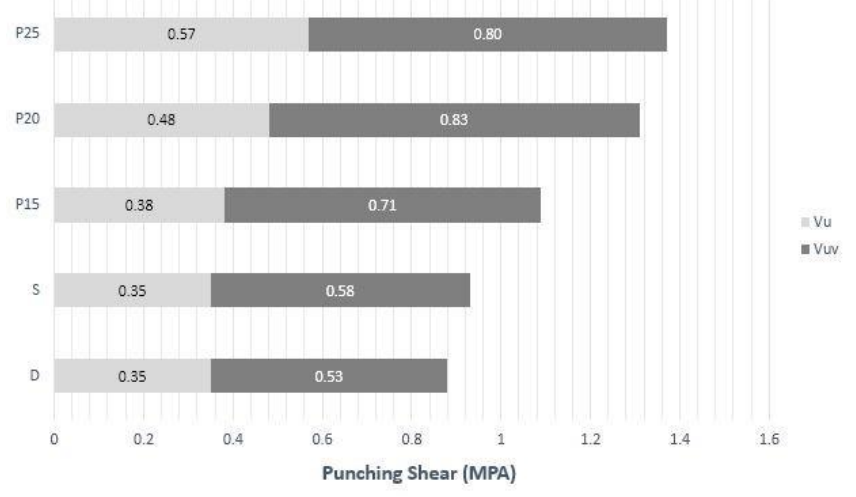

Figure 25: Average punching shear stress in $\mathrm{G}+7$

\section{Conclusions}

Three dimensional linear time history analysis is performed on flat slab with different structural configurations using 10 unscaled ground motion records. In particular, the following observations are made:

- We found significant effects of vertical seismic ground motions on the response of flat slab structure.

- We found maximum of $266 \%$ of axial force due to vertical acceleration with compare to gravity loads.

- It is also noted that effect of vertical seismic force on axial loads in column increases in central columns while it uniformly decrease in outer periphery columns.

- We found maximum $370 \%$ increase in slab deflection with compare to gravity forces.

- We also demonstrate that providing shear wall cannot decrease vertical displacement of structure as it can decrease lateral displacement of structure, although we have provided shear wall at corners only, on other locations its effectiveness against vertical acceleration need to be checked.

- It is noted that major devastating effects of vertical acceleration is on punching shear in flat slab structure and it is depends on thickness of slab.

- We found maximum $2.2 \mathrm{~N} / \mathrm{mm}^{2}$ punching shear stress only due to vertical seismic force. In terms of percentage maximum $525.7 \%$ of punching stress is increased which is enough to lead progressive collapse of any flat slab.

- In flat slab structure generally lateral seismic force is either fully resisted by shear wall or partially resisted by perimeter SMRF while internal columns are designed as gravity columns, but it will be risky under vertical seismic force to design internal columns as gravity columns.

\section{Acknowledgement}

I express my sincere thanks to Prof. Dipak K. Jivani for their utmost guidance and motivation on both research as well as on my career.

\section{References}

1. A.J. Papazoglou and A. S. Elnashai (1996), Analytical and field evidence of the damaging effect of vertical earthquake ground motion, Earthquake engineering and structural dynamics, vol. 25, 1109-1137 (1996).

2. A.S. Elnashai and A.J. Papazoglou, (1996), Procedure and spectra for analysis of RC structure subjected to strong vertical earthquake loads, journal of earthquake engineering vol. 1 , no. 1, 121-155.

3. B. Alavi and H. Krawinkler (2004), Behaviour of moment-resisting frame structures subjected to near fault ground motions, earthquake engineering and structural dynamics,2004; 33:687-706 
4. Bipin Shrestha (2009), vertical ground motions and its effects on engineering structures: a state-of-the-art review, international seminar on hazard management for sustainable development.

5. Bozorgnia Y., K. W Campbell, M. Niazi (1996), Relationship between vertical and horizontal response spectra for the Northridge earthquake, Elsevier science ltd, paper no. 893. 11WCEE.

6. Bozorgnia Y., K. W Campbell (2004), The vertical to horizontal response spectral ratio and tentative procedures for developing simplified $\mathrm{V} / \mathrm{H}$ and vertical design spectra, Journal of earthquake engineering, Vol. 8, No. 2, 175-207.

7. C. J. Collier, A. S. Elnashai (2001), A Procedure for combining vertical and horizontal seismic action effects, Journal of earthquake engineering, Vol. 5, No. 4, 521539.

8. Hongliu Xia, J. Lin, J. Han, Yingmin Li \& Yuntian Wu (2012) study on seismic behavior of frame structures considering effect of vertical earthquake motion, 15th WCEE.

9. Hossein Abdollahiparsa, P. Homami, and F. Khoshnoudian (2016) effect of vertical component of an earthquake on steel frames considering soil structural interaction, KSCE Journal of civil engineering (2016) 20(7):2790-2801.

10. L. Di Sarno, A.S. Elnashai, G. Manfredi (2011) Assessment of RC columns subjected to horizontal and vertical ground motions recorded during the 2009 L'Aquila (Italy) earthquake, Engineering Structures 33 (2011) 1514-1535.

11. P. C. Shaha, P. Kamatchi and C. B. Nayak (2018) Effect of Vertical Ground Motions on the Response of Long Span Roof Truss, 16th Symposium on Earthquake Engineering, December 20-22, 2018, IIT Roorkee, Paper No. 57.

12. Siyun Kim, S. J. Kim, and C. Chang (2018) Analytical Assessment of the Effect of Vertical Ground Motion on RC Frames Designed for Gravity Loads with Various Geometric Configurations, Hindawi, Advances in Civil Engineering, Volume 2018, Article ID 4029142, 11 pages

13. Weng Y. Kam, S. Pampanin, K. Elwood (2011) Seismic performance of reinforced concrete buildings in the 22 February Christchurch (lyttelton) earthquake, bulletin of the New Zealand society for earthquake engineering, vol. 44, no. 4.

\section{Biographical notes}

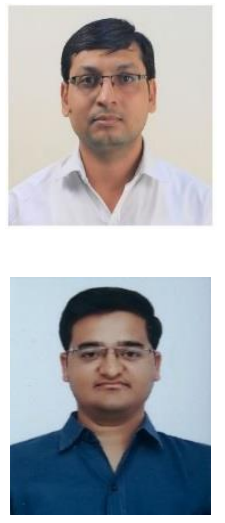

Prof. Dipak K. Jivani obtained M.Tech. (Structure) in 2008 from Nirma University. He has been associated with Darshan Institute of Engineering and Technology-Rajkot since January, 2013 and presently working as Assistant Professor. He has Eight years of experience including Profession experience at TATA Consulting Engineers. He has professional experience on structural designing of various industrial structures, multi storied residential buildings, Machine Foundations and water retaining structures. His areas of interest include Earthquake engineering, Structural Dynamics, Structure analysis and Design.

Jaydeep H. Chotaliya is final year student of Darshan institute of engineering \& technology, he is doing his M.E. in structural engineering from Gujarat technological university. 